\title{
A CINCUENTA AÑOS DE LA UNIDAD POPULAR: EL ALLENDISMO COMO TEORÍA POLÍTICA
}

\author{
Ernesto Águila Zúniga
}




\section{ERNESTO ÁGUILA ZÚÑIGA}

Doctor en Educación. Profesor asociado de la Facultad de Filosofía y Humanidades de la Universidad de Chile y docente e investigador del Departamento de Estudios Pedagógicos. Actualmente es director de Extensión y Comunicaciones de la Facultad de Filosofía y Humanidades y miembro del Centro de Estudios de Ética Aplicada (CedeA) del Departamento de Filosofía. Sus áreas de investigación son los vínculos entre educación y democracia, teoría de la ciudadanía, cine y educación, y, en el campo de la teoría política, el pensamiento socialista chileno. 


\section{A CINCUENTA AÑOS DE LA UNIDAD POPULAR: EL ALLENDISMO COMO TEORÍA POLÍTICA}

A partir de la conmemoración de los cincuenta años del triunfo de la Unidad Popular (UP) el pasado 4 de septiembre de 2020, se abrió un conjunto de reflexiones y debates sobre el significado de esta experiencia. Un hecho significativo fue que la fecha a conmemorar trasladó el eje de interés desde la derrota al triunfo de la UP. Ello motivó a conocer más sobre los años de gobierno de la UP, así como sobre el proceso de construcción política que la antecedió y que condujo al 4 de septiembre de 1970.

A su vez, esto permitió revisitar y revisar con más profundidad el liderazgo de Salvador Allende; no dejarlo petrificado en su gesto final o en algunos de sus grandes discursos, sino reconocerlo y analizarlo como un líder constructor, durante décadas, de un proyecto y de un movimiento político, social y cultural que desembocó en la Unidad Popular. El allendismo, entendido así como la configuración de un programa, de un nuevo bloque histórico y de una estrategia de disputa del poder original dentro de lo que era el pensamiento de la izquierda de la época.

Una pregunta relevante que ha sobrevolado estos actos conmemorativos es de qué manera la experiencia de la UP puede ser leída y recuperada en el presente. Esta interrogante se ha respondido de diversas formas: entenderla como una experiencia histórica relevante pero circunscrita estrictamente a su tiempo, en una operación simultánea de reconocimiento y clausura; aquilatarla como un momento utópico y heroico, recuperarla desde una perspectiva romántica y estética; abordarla desde una memoria abierta, que podríamos caracterizar como inspiradora.

Todas estas respuestas son posibles y han estado presentes en las reflexiones y debates, pero quisiéramos en el presente trabajo sostener que la experiencia de la UP y el allendismo pueden entenderse también como la configuración incipiente de una "teoría política", es decir, que es posible identificar en ese conjunto de ideas originales y prácticas sociopolíticas que conformaron la experiencia allendista, un intento de dar respuesta de una manera distinta a un conjunto de problemas teóricos sobre el poder y el Estado; acerca de los medios para realizar el socialismo (el viejo dilema de reforma o revolución); las relaciones entre lo social y lo institucional; y el vínculo entre democracia y socialismo; entre otros, que han cruzado la historia de las ideas de la izquierda, tanto en nuestro país como en Latinoamérica y el mundo.

El reconocimiento del allendismo como una teoría política posible, su (re) construcción y sistematización en esos términos, abre una dimensión distinta de 
cómo entender la experiencia de la UP, su gobierno y su conformación previa, en tanto extrae el fenómeno de su sola historicidad para reconducirlo al ámbito teórico, lo que le da otro sentido o presencia al allendismo en el presente.

Si el allendismo puede ser entendido también como una teoría política, significa que puede ser trabajado no solo desde la historia o la memoria — que es donde más se lo ha abordado y elaborado_-, sino también desde la esfera propiamente teórica. Lo que significa un conjunto de tareas propiamente teóricas, como una mejor delimitación de su objeto de estudio; una necesaria actualización de sus conocimientos y formulaciones — sin afectar sino reafirmando su especificidada las nuevas condiciones de la realidad social y económica; y un trabajo sobre sus debilidades y vacíos.

\section{ALLENDE COMO CONSTRUCTOR DE PENSAMIENTO POLÍTICO}

Si el allendismo puede considerarse no solo un movimiento histórico sino también una teoría política, se debe partir por reconocer a Allende como un intelectual. Cortés Terzi (1988) es uno de los pocos autores que ha reconocido a Allende como un "creador de pensamiento". Para fundamentar esta afirmación se ha valido de la definición de intelectual de Gramsci, quien extiende dicha categoría a todos quienes participan de un proyecto colectivo histórico donde se amalgaman la producción de ideas y la práctica, las funciones directivas, organizativas, educativas:

"Dos grandes rasgos (identifican) a Allende como un intelectual. Primero como creador de cultura política. Sin duda, que fue uno de los más importantes y eficientes creadores de sentimientos y voluntades socialistas entre las masas chilenas. A decir de Gramsci, hizo 'historia concreta y completa' y, por ende, formó parte activa de la 'filosofía de una época'. Y segundo, como dirigente y organizador de esos sentimientos y voluntades" (íbid.: 9).

Es decir, en el ejercicio de su liderazgo político, Allende realizó una actividad intelectual en tanto constructor de un movimiento político histórico, pero junto a esta tarea organizativa y directiva fue formulando un proyecto político-teórico propio acerca de cómo debía realizarse el socialismo en Chile, dando vida a un conjunto de categorías interpretativas propias de la realidad y sobre la transformación social en Chile.

La llamada "vía chilena al socialismo" fue un desafío político que planteó problemas teóricos e interrogó ciertas concepciones filosóficas y teóricas tradicionales de la izquierda, tanto en su vertiente revolucionaria (comunista) 
como socialdemócrata (reformista). Allende, con gran ambición no solo política sino también teórica, sostuvo que su proyecto significaba un segundo modelo de transición al socialismo ${ }^{1}$, aludiendo así a la distancia y ruptura de su vía con el "primer modelo", que era el modelo leninista y de la revolución rusa.

En este sentido, planteó que en el camino al socialismo no era una ley ineluctable de la historia tener que pasar por una fase de dictadura para transformar la sociedad en una dirección socialista, y que dicho tránsito podía hacerse a través de la institucionalidad y la legalidad democrática. Justo es decir que un componente esencial en la estrategia allendista era también la construcción de un pueblo, organizado y consciente, transformado en un sujeto político que tensionaba esa legalidad desde una demanda de mayor legitimidad democrática. En este sentido, la estrategia allendista no era solo institucional, pero su apego a la institucionalidad democrática era un componente esencial.

Cabe señalar que la "vía chilena" y el allendismo no eran una formulación política general sobre el cambio socialista, es decir, concebido para cualquier lugar y circunstancia histórica, sino que estaba pensada para sociedades como la chilena, en las que se diagnosticaba la existencia de una maduración de la institucionalidad democrática y del Estado de derecho capaces de permitir su propia autotransformación y superación. En ese sentido, el allendismo era una formulación teórica para sociedades cuyo desarrollo económico y político-institucional habían alcanzado cierta madurez. Alcanzar dicha consolidación institucional, esa porosidad democrática, era también parte consustancial de la vía propuesta.

Parte de la vigencia, no solo política sino teórica del allendismo, es que hoy es muy difícil que un movimiento de izquierda, en Latinoamérica y en el mundo, pueda plantearse una vía de acceso al poder distinta a la democrática. Si existe o no una segunda forma de transición al socialismo puede seguir siendo controvertido, pero lo cierto es que la llamada primera forma de transición al socialismo resulta irrepetible.

Sin embargo, la idea de utilizar el propio Estado democrático liberal para salir de un modo de producción y de relaciones de poder capitalista, implicaba ayer, y en parte hoy, una herejía teórica importante, porque suponía una concepción del Estado en la cual este no solo fuera entendido como un instrumento de dominación de una clase sobre otra, sino un espacio en disputa o susceptible de ser disputado.

1. En su primer mensaje al Congreso pleno de 1971, Allende formuló esta tesis. Específicamente, señaló: "Chile es hoy la primera nación de la Tierra llamada a conformar el segundo modelo de transición a la sociedad socialista” (en Arrate y Ruiz, 2020: 75). 
Esto hoy no resulta tan herético, toda vez que existe un mayor predominio de concepciones del derecho y del Estado dentro del pensamiento de izquierda y progresista que lo conciben como formas institucionales y normativas capaces de evolucionar, y que en su propia conformación histórica se ha ido inscribiendo la conflictividad social y de clases. Ni el Estado ni el derecho constituyen estructuras estancas y puras en su signo de dominación. Especialmente, como ya hemos dicho, en sociedades donde se ha profundizado la democracia y sus instituciones y estas se han vuelto más porosas para ir expresando nuevas relaciones de poder en su interior y en la propia sociedad.

Para ejemplificar mejor el punto, veamos esta cita de Poulantzas en su debate con Althusser (este último muy influyente teóricamente en el periodo de la UP):

"Contra esta concepción esencialista (la de Althusser) yo había propuesto que el Estado se considerase como una relación, más exactamente como la condensación material de una relación de fuerzas entre las clases y fracciones de clases. El poder mismo no es una esencia cualificable, sino una relación. El Estado se haya propiamente constituido por las contradicciones internas del mismo (...). Más que en términos de adentro o afuera es preciso razonar en términos de terreno y procesos estratégicos: las luchas populares, bajo sus aspectos políticos, se sitúan siempre en el terreno del Estado" (Poulantzas, 1980: 172).

No cabe duda de que esta visión, más relacional y no esencialista del Estado, resulta más comprensiva y ajustada a una estrategia socialista que busca apoyarse en la institucionalidad para producir una transformación social estructural. Sin embargo, siendo esta una concepción que podría haber estado presente en el periodo de la UP, no fue parte de las visiones dominantes.

Las visiones teóricas que el allendismo tenía a su base —aunque con una insuficiente formulación y sistematización - tuvieron una escasa comprensión en el mundo político e intelectual de su época, demasiado dominado por una ortodoxia teórica en su forma tradicional o bien estructuralista². Cortés Terzi (1988) llama la atención sobre la orfandad teórica del allendismo, una cierta fría recepción y

2. Un trabajo pendiente es analizar las concepciones teóricas predominantes en los sesenta y en el periodo de la UP. Una de estas era, sin duda, la lectura estructuralista marxista de Althusser, defendida y difundida en Chile por Marta Harneckner. No cabe duda de que una estrategia como la vía chilena no se facilitaba con el estructuralismo, toda vez que el allendismo ponía mucho más el acento en los sujetos políticos, la subjetividad social y en la historicidad de los procesos y de las instituciones. 
distancia de la intelectualidad de la época con la "vía chilena". El allendismo desafiaba demasiado las concepciones teóricas dominantes como para reconocerle un estatus teórico a su planteamiento y trabajar en torno a desentrañar las contradicciones y dificultades propiamente teóricas que la estrategia allendista implicaba. Cortés Terzi sentencia al respecto: "siendo el allendismo la síntesis más significativa del desarrollo popular chileno, nunca dispuso de una intelectualidad que la fortaleciera y proyectara" (íbid.: 10). Reconozcamos que se trataba de una "teoría política" incipiente e insuficientemente sistematizada, con un claro rezago en su formulación teórica.

Por otra parte, el allendismo y algunas de sus "heréticas" propuestas políticas y teóricas no nacían en un vacío histórico, sino que hundían sus raíces en el desarrollo de la izquierda del siglo XX y del movimiento obrero y popular, en particular de la vertiente socialista chilena, donde se había ido incubando un conjunto de planteamientos originales y heterodoxos, a partir del cual el allendismo se nutre. $\mathrm{O}$ quizá puede ser dicho a la inversa: ese pensamiento socialista original encuentra en el allendismo su proyección y, algo muy importante, su posibilidad de encarnar en la cultura popular chilena y en un movimiento histórico social concreto.

\section{GENEALOGÍA DEL ALLENDISMO: EL ENTRONQUE TEÓRICO Y POLÍTICO CON EL DESARROLLO DEL PENSAMIENTO DEL SOCIALISMO CHILENO}

El allendismo como práctica política, pero sobre todo como teoría, tiene tras de sí la larga trayectoria de la izquierda y del movimiento popular chileno. Pero, sin duda, un antecedente fundamental lo constituye la singularidad política y conceptual del Partido Socialista ${ }^{3}$.

¿Cuáles son algunos de estos rasgos del socialismo y del Partido Socialista que más influencia tuvieron en la conformación posterior del allendismo? Destacaremos las siguientes: la perspectiva de entroncar las ideas socialistas en la historia nacional y en una cierta interpretación de esta; la reafirmación de un ideario democrático, que aunque resignificaba su formulación liberal desde una perspectiva socialista, se fue concibiendo, particularmente en la fase allendista, como indisoluble e irrenunciable

3. No todos quienes han estudiado la trayectoria del socialismo chileno realizan este vínculo entre el socialismo de las primeras décadas y el allendismo. Uno de quienes con más profundidad y rigor construye este nexo es Belarmino Elgueta, quien es crítico del periodo en que el PS se define marxista-leninista (a partir de los sesenta) y, luego, de la renovación socialista (a fines de los setenta). La "herencia yacente" es, para él, aquella que construye el primer socialismo y luego el allendismo (véase Elgueta, 2015). 
en la construcción del socialismo; una reafirmación anticapitalista, lo que unido a su vocación democrática generaba una suerte de "reformismo revolucionario"; una conexión entre principios y doctrina, por un lado, y una práctica de soluciones concretas para el mundo popular y de trabajadores, por otro, que generaba una combinación donde lo ideológico no era obstáculo para establecer un vínculo con la realidad social concreta; una perspectiva libertaria y autónoma en un amplio sentido, desde lo teórico hasta la visión de los temas internacionales.

El trabajo de interpretación histórica que realizan en los años veinte, y en décadas posteriores, algunos de los principales fundadores del socialismo chileno, incluido el propio Allende, da cuenta de la voluntad de conectar las ideas socialistas con una lectura de la historia larga de Chile. Por ello da una valoración especial a personajes como Arcos y Bilbao y la Sociedad de la Igualdad durante el siglo XIX, o el rescate que realizan del "nacionalismo económico" de Balmaceda o, incluso, de Alessandri Palma en la coyuntura antioligárquica de 1920. Ello resulta interesante, pues las ideas socialistas se constituyen así dentro de un continuo histórico de la sociedad chilena ${ }^{4}$.

Dicha perspectiva socialista permitirá al allendismo, posteriormente, formularse en continuidad con las tradiciones progresistas chilenas, siendo parte de estas y resaltando el carácter nacional del socialismo chileno.

Un segundo aspecto a destacar es la reafirmación de la democracia en el desarrollo de la idea socialista. Si bien la declaración fundacional del PS en 1933 habla de una "dictadura de los trabajadores", esta definición es "corregida" en el programa de 1947 y se asienta teóricamente como la perspectiva socialista dominante ${ }^{5}$. Es una democracia de trabajadores tensionada con el liberalismo y sus formalidades, junto a un humanismo socialista en oposición a un humanismo burgués, siendo inequívocamente una reafirmación del ethos democrático dentro del ideario socialista. A su vez, la distancia explícita que el socialismo chileno adopta frente a la experiencia soviética y el estalinismo en los años cuarenta y cincuenta, y la

4. El historiador socialista Julio Cesar Jobet escribe sobre Arcos y la Sociedad de la Igualdad, Eugenio Matte y Salvador Allende sobre Balmaceda. Hay un esfuerzo por conectar el socialismo con el liberalismo más jacobino y progresista del siglo XIX. Para una selección de artículos en esta dirección, véase Arrate y Ruiz (2020: 28-35).

5. Posiblemente, los dos textos oficiales que mejor configuran la fisonomía política y teórica del PS son la Declaración de Principios de 1933 y la Fundamentación teórica del programa del 47, redactada por Eugenio González. En general, ambos textos deben leerse de manera complementaria, pero donde se produce una ruptura es en el abandono del término "dictadura de los trabajadores" de la declaración del 33. El programa del 47 enfatiza el carácter democrático del socialismo chileno, tanto en su vía como en el contenido de ese socialismo. Para una lectura de la fundamentación del programa del 47, véase Arrate y Ruiz (2020: 122). 
crítica a sus formas burocráticas y autoritarias, reafirmará esta identidad democrática del proyecto socialista chileno.

Un tercer aspecto es que el socialismo chileno fue, desde sus orígenes, una propuesta de transformación estructural de la sociedad de signo anticapitalista y antifeudal (la importancia del tema del latifundio), bajo la idea-fuerza de una recuperación de la soberanía económica. También mantuvo un sentido de apego constante a una realidad social identificada con el mundo de los trabajadores con sentido de clase. Esto último, lo hizo desde una apertura anticipada de los cambios que comenzaban a verificarse en la estructura social postoligárquica y de ascenso de nuevos grupos medios. Su acendrado sentido de clase no reducía el tema del pueblo al mundo obrero, sino a una percepción de lo social más amplia y que se resumió en aquella fórmula de "trabajadores manuales e intelectuales" de la Declaración de Principios de 1933 del Partido Socialista (véase Arrate y Ruiz, 2020: 83).

Un cuarto aspecto a señalar es esa particular ecuación del socialismo chileno de combinar una posición doctrinaria con la sensibilidad y apertura ante los problemas sociales del mundo popular y de trabajadores. En este sentido, una política de principios no era vista de forma contrapuesta a una política de realización de acciones concretas de bienestar social. Ello se observa en la valoración que algunas de las principales figuras del socialismo realizan de su participación en la experiencia de la "república socialista" de los 12 días de 1932, la que en su breve lapso realizó un conjunto de acciones en beneficio del mundo popular.

$\mathrm{Al}$ respecto, valga señalar esta cita de uno de los fundadores del socialismo chileno, Eugenio Matte, refiriéndose a este tema: "Más que principios nosotros traíamos soluciones y las soluciones de hoy son las que engendran los principios que habrán de dar cauce doctrinario a nuestra revolución" ". Una interesante y sugerente fórmula para entender la relación entre principios y demandas sociales urgentes, y que será recogida en la práctica posterior del allendismo.

Un quinto aspecto distintivo es el valor de la autonomía, en un sentido amplio, que instala esta corriente socialista. Ya lo mencionamos en su posicionamiento internacional, pero también en su propia relación con la teoría, y que se expresa en la fórmula "adhesión a un marxismo enriquecido y rectificado por el constante devenir social"”. Esta definición lo aleja de una concepción escolástica de la teoría, donde la acción política se realiza desde un corpus teórico preconstituido y se concurre a la realidad para verificar dicha teoría. Por el contrario, la fórmula indica

6. Entrevista a Eugenio Matte en el diario La Nación de Argentina, en 1932, a propósito de la experiencia de la República Socialista de los 12 días (en Arrate y Ruiz, 2020: 50).

7. Declaración de Principios de 1933 (íbid.: 83). 
que se confronta a la realidad desde una posición teórica abierta y que la realidad puede transformar constantemente dicha teoría a partir de las condiciones que allí se verifican. Esta visión abierta de lo teórico es, sin duda, una actitud intelectual que marcará después la libertad y autonomía con que el allendismo se relacionará con la comprensión de la realidad, asumiendo una gran soltura y libertad de análisis y teórica.

Como es sabido, a lo largo del siglo XX, la izquierda chilena y mundial se bifurcó en tres grandes corrientes: anarquista, comunista y socialdemócrata. En el caso latinoamericano, hacia los años treinta se fue configurando una vertiente nacional-populista y, más tarde, en los sesenta, una corriente guevarista inspirada en la revolución cubana. Cada una de ellas tenía tras de sí una teorización sobre el Estado, sobre el poder, sobre la revolución, la transformación social y sobre los medios para alcanzar sus objetivos.

El socialismo chileno se diferenció y resolvió de una manera distinta estas grandes encrucijadas de la izquierda. En algunos aspectos teórico-prácticos se acercó más a una de las vertientes y en otros aspectos a otras, pero en su síntesis final mantuvo una originalidad que la hizo distinta y no asimilable a ninguna de ellas.

Tuvo una importante influencia de corrientes anarquistas e incluso algunos de sus más destacados líderes tuvieron esa procedencia, pero no tuvo la visión antiEstado del anarquismo. Receló del Estado, pero en su diseño estratégico el componente institucional y el propio Estado tenían una centralidad importante en la reafirmación de la soberanía económica del país.

No fue tampoco socialdemócrata, porque su vocación anticapitalista fue más acendrada, aunque podría reconocerse una cierta cercanía por su adscripción a la idea de que el proyecto socialista debía avanzar por medios democráticos. Pero la radicalidad socialista del allendismo tensionaba más fuertemente que la socialdemocracia la relación con la democracia liberal.

Tampoco puede asimilarse el socialismo chileno a la vertiente comunista. En gran medida el PS se construye en debate y diferenciación con esta. Pero sí se acercaba en su concepción anticapitalista y en una cierta visión de clase, lo que llevó a la formulación posterior de una política de unidad de la izquierda cuyo eje era la alianza PS y PC.

Con los movimientos nacional-populistas el socialismo chileno compartió una cierta perspectiva de lo nacional y de lo latinoamericano y la urgencia de las demandas sociales, pero fue más doctrinario que estos, y la configuración del sistema de partidos chilenos mantuvo más fuerte la frontera entre derecha e izquierda que en otros países latinoamericanos. Por último, mantuvo cercanía y simpatía con los dirigentes y causas de la experiencia cubana y de los movimientos a los que dio origen en América Latina producto de su posición internacional no alineada, pero 
su bifurcación en términos de estrategia y formas de lucha fue evidente y explícita. La "vía chilena al socialismo" no consideraba entre sus componentes la lucha armada ni la guerrilla.

El socialismo chileno se movió así en términos teóricos y prácticos de manera diferenciada de las grandes corrientes de la izquierda latinoamericana y mundial, construyendo su propia síntesis. De ese afluente doctrinario y político surgirá y se nutrirá el allendismo.

\section{ORIGINALIDADES POLÍTICAS DEL ALLENDISMO Y SU CONFORMACIÓN COMO TEORÍA}

Entenderemos el allendismo como aquella fase histórica que tiene su origen en la elección presidencial de 1952 y que concluye en 1973. Allende ya era en 1952 un político experimentado y con una importante trayectoria (exministro, expresidente de partido y parlamentario). Sin embargo, su primera presentación como candidato presidencial en las particulares condiciones de 1952, en contra de la mayoría de su propio partido (el cual, bajo la denominación de Partido Socialista Popular, apoyó a Ibáñez), se puede considerar como el momento fundacional de un proyecto y el inicio de un nuevo ciclo histórico, que luego se expresará en sucesivas candidaturas presidenciales hasta el triunfo de 1970.

En esta etapa, Allende encarnará las ideas socialistas en el mundo popular y trabajador chileno y entrelazará la cultura popular en la cultura nacional. Pero dicho proceso, que ya en sí mismo es de naturaleza intelectual, irá dando forma a un pensamiento político sobre la transformación socialista para Chile que irá alcanzando un tipo de universalidad que permite reconocerla — a nuestro juiciocomo una teoría política en ciernes.

A continuación, quisiéramos destacar ciertos aspectos políticos que caracterizaron al allendismo y que nos parece pueden considerarse generadores de una teoría política específica.

1. En primer término, conviene insistir en la idea de que el allendismo puede ser formulado como una teoría política para sociedades en que el componente

8. Fechar el inicio del allendismo en 1952 es una opción que se fundamenta en que esta es la primera campaña presidencial de Salvador Allende, con la que se inicia más formalmente la conformación de su liderazgo nacional. La elección de 1952, aunque en sus resultados resulta testimonial, constituye una reafirmación de una voluntad programática socialista y de una alianza de izquierda con eje en el entendimiento PS-PC que será predominante en las décadas siguientes (Águila, 2020). 
democrático liberal ha alcanzado un desarrollo significativo, en que existe una maduración de la institucionalidad democrática.

En este sentido, se trataría de una teoría

"en el marco de una sociedad políticamente desarrollada, con prácticas y valores democráticos arraigadas en la estructura social (...). Con lo que delimitamos nuestro campo visual a los países que han experimentado de una u otra forma la revolución democrática liberal, históricamente vinculada al desarrollo del capitalismo industrial y de los conflictos sociales entre burguesía y clase obrera" (Garcés, 2013: 17).

De esta cita nos interesa destacar no tanto la caracterización de la estructura social que hace Garcés, y que bajo la revolución neoliberal de los años ochenta del siglo pasado tomó derroteros distintos a la consolidación de una sociedad industrial de base obrera, sino relevar la dimensión institucional democrática que allí se señala como fundamento para el desarrollo de una vía institucional al socialismo. Sin esa maduración institucional, en que las contradicciones y el avance hegemónico de las ideas socialistas no se reflejen en algún grado en el propio aparataje estatal, no es posible pensar un tránsito democráticoinstitucional como el que propuso el allendismo.

2. La centralidad que adquiere la concepción de un socialismo nacional en la propuesta allendista. La vía institucional requiere conectar la evolución social histórica de un país con las ideas socialistas. La lectura e interpretación propia de la historia nacional se transforma así en un componente esencial de la construcción de este proyecto. Una vía institucional requiere el desarrollo creciente de una transformación de la cultura popular y socialista en cultura nacional. La porosidad del Estado y de las instituciones se basa en que se reconozca al socialismo como parte de la propia evolución histórica de esa sociedad y de ese Estado.

3. Al no abandonar el allendismo la contradicción capitalismo/socialismo y pretender resolverla de manera democrática, el derrotero estratégico termina planteando una contradicción entre capitalismo y democracia (o, dicho en términos actuales, entre mercado y democracia). La idea de justicia e igualdad que encarna el socialismo no contradice la democracia, sino que la sustantiviza, la tensiona en sus promesas de libertad e igualdad universal. En este sentido, el socialismo por vía institucional es una profundización y radicalización democrática. La relación entre democracia y socialismo que plantea el allendismo 
es un aspecto a continuar trabajando teóricamente, porque la democracia no puede ser vista solo como un medio para lograr el objetivo socialista, sino también como parte integrante de la construcción de este. No es un aspecto instrumental, sino consustancial al socialismo que se propone.

4. El allendismo se aparta de la idea de que el tránsito al socialismo requiera de una etapa de dictadura transitoria. Como lo señala Allende en su discurso del 21 de mayo de 1971:

"El pueblo de Chile está conquistando el poder político sin verse obligado a utilizar las armas. Avanza en el camino de su liberación social sin haber debido combatir contra un régimen despótico o dictatorial, sino contra las limitaciones de una democracia liberal. Nuestro pueblo aspira legítimamente a recorrer la etapa de transición al socialismo sin tener que recurrir a formas autoritarias de gobierno" (Allende, 1971).

Es interesante en la cita la identificación como el verdadero adversario a "las limitaciones de la democracia liberal". Lo que reafirma la centralidad de la reflexión sobre la democracia y que la transformación de la propia institucionalidad es condición para viabilizar una estrategia democrática al socialismo.

A su vez, esta formulación implica una profundización y complejización de la teoría del Estado y del poder. Quizás este es el punto nodal para que el allendismo pueda derivar en teoría política. Una teoría del Estado y del derecho que los reconozca no solo como instrumentos de dominación, sino también como el lugar donde se expresan las contradicciones y luchas históricas, donde la conflictividad social y las disputas hegemónicas van quedando inscritas. Y a partir de esto, identificar las condiciones y formas de transformación de la institucionalidad para una socialización del poder y una transformación de la economía en una dirección socialista. Ponderar la maduración del Estado y de la institucionalidad es parte del programa transformador de la sociedad y de la estrategia política. No es posible avanzar en la transformación económica y social si no se va transformando el propio Estado, el derecho y la institucionalidad.

Muchos de estos aspectos no fueron bien comprendidos ni resueltos en el periodo 70-73. Una parte de la izquierda no entendió que el respeto a la legalidad democrática era fundamental para posibilitar el cambio y que cualquier fuerza

9. Mensaje al Congreso pleno, 21 de mayo de 1971 (en Arrate y Ruiz, op. cit.: 275). 
o poder social que se pudiera constituir no podía ser en contra de la propia institucionalidad y legalidad democrática. Sin una claridad estratégica básica en este aspecto, no es posible pensar la posibilidad de un socialismo por vías democráticas e institucionales.

5. El allendismo se caracterizó por la conformación del pueblo en un sujeto político. Constituyó un tipo de política que daba especial protagonismo a los actores sociales. Un tipo de relación muy lejana a las actuales formas clientelares que se dan entre política representativa y sociedad. Un aporte de una teoría política allendista sería profundizar en esta concepción particular de relación entre política, sociedad y pueblo.

6. El allendismo fue revolucionario en sus objetivos, pero gradual en sus medios, y dicha gradualidad es intrínseca a los mecanismos, tiempos y parsimonias propias de la democracia. Planteó así un "reformismo revolucionario". Lo revolucionario estaba en sus objetivos, lo que lo distanciaba de la socialdemocracia, pero en sus medios buscaba realizarlo a través de sucesivas reformas democráticas unidas a ese protagonismo popular que le era inherente. Se debería profundizar teóricamente en las prácticas políticas capaces de generar transformaciones sociales y culturales. Desarrollar una teoría del cambio social.

7. Al referirse en la "vía chilena al socialismo" al significado del voto popular, se suele formular de manera negativa como "no es solo una estrategia electoral”. Sin embargo, se debe asumir que el voto popular es parte del núcleo estratégico del allendismo. Si el allendismo tiene en su centro valerse de la propia legitimidad democrática para producir las transformaciones, ello significa una especial preocupación por la soberanía popular, pues allí radica el principio de legitimidad en una democracia. Para las fuerzas conservadoras, la existencia de un voto emancipado fue lo que posibilitó la Unidad Popular, y contra ello se erigió la Constitución de 1980 y los llamados mecanismos contramayoritarios.

8. La estrategia allendista implicaba un concepto de hegemonía bien desarrollado teóricamente. La lucha se da en términos estrictamente democráticos, pero no es solo un juego electoral, sino que hay un proyecto histórico que busca transformarse en sentido común en la sociedad. La disputa electoral se acompaña de una disputa cultural. El allendismo recoge con centralidad la reflexión gramsciana sobre hegemonía y todas aquellas teorías que significan ir anticipando el cambio en la sociedad antes de su concreción institucional. La idea de anticipación cultural y hegemónica es central en una estrategia democrática e institucional. 
9. Ideología y principios no debieran contraponerse a la realización y solución de medidas urgentes del mundo popular y de trabajadores. El allendismo se construyó desde ciertos principios, pero ello no fue obstáculo para proponer e intervenir de manera concreta en la solución de los problemas sociales más acuciantes. De allí su arraigo y conexión con lo popular. En ese sentido, una visión de transformación estructural no puede ser obstáculo para gobernar el presente. Lo que debería diferenciarse de simplemente administrar el presente. El allendismo implica una visión política antielitaria y una conexión con lo popular muy estrecha.

10. En el allendismo, el concepto de socialismo fue central. Un significante que estructuraba su idea de futuro. Es cierto que hoy no es fácil describir con precisión, en términos de horizonte histórico y de tipo de sociedad, lo que implica el socialismo. Reponerlo como concepto cardinal significa conocer más profundamente el tipo de sociedad que pretende hoy superar, así como los rasgos y formas de organización social y económica que este implicaría. El allendismo se alimentó de las teorías de la dependencia de los sesenta. No debieran considerarse estas visiones obsoletas, pues la globalización neoliberal ha acentuado, bajo nuevas formas, las relaciones de subordinación entre centro y periferia. Repensar la soberanía económica del país en el marco de la actual interrelación mundial y hacerlo desde Latinoamérica constituyen contenidos allendistas tradicionales que debieran actualizarse para las nuevas condiciones históricas ${ }^{10}$. Pero, sin duda, hoy una idea de socialismo debe pensarse desde los aportes de otras corrientes como el feminismo, el ecologismo o ciertas visiones del comunitarismo, entre otras.

Reconstruir la idea misma de socialismo para esta nueva etapa de Chile y del mundo se constituye en un desafío teórico y político fundamental dentro de esta noción neoallendista que hemos esbozado en este trabajo.

\section{A MODO DE CONCLUSIÓN}

La idea central que aquí hemos trabajado propone comprender el allendismo no solo como una etapa de nuestra historia, sino que este tendría ciertas características que le permitirían devenir en teoría política. Que en sus formulaciones originales y en la

10. Revisitar la obra de Enzo Faletto resulta fundamental desde la perspectiva de reconstruir una visión de socialismo latinoamericano. No cabe duda de que Faletto puede considerarse como parte del ethos teórico del allendismo (véase Faletto, 2016). 
manera como intentó resolver ciertas cuestiones y dilemas clásicos de la izquierda hay en potencia un pensamiento que puede ser formulado a la manera de una teoría.

Como tal, requiere, por un lado, fijar mejor sus contornos y aquello que le es propio y que lo diferencia de otras formulaciones teóricas que buscan resolver problemas y dilemas similares en la izquierda y, por otro, trabajar sus insuficiencias y vacíos teóricos y actualizarse en función de las nuevas realidades nacionales e internacionales.

Su confirmación y consolidación como teoría requiere que este demuestre capacidad para analizar el presente, distinguiendo aquello que es parte de su propia historicidad de lo que pueden considerarse categorías permanentes allendistas de análisis de la realidad y de formulación de soluciones y alternativas. La propuesta del allendismo como teoría política es, por tanto, hoy más una posibilidad que una realidad plena y consolidada. Pero de lograr sortear los problemas propios de una teoría, el allendismo adquiriría una dimensión y un significado inédito dentro del pensamiento político y teórico de la izquierda y del socialismo chileno. 


\section{REFERENCIAS}

Águila, E. (4 de septiembre de 2020). "La construcción del 4 de septiembre de 1970”, El Siglo.

(2017) El Partido Socialista y la compleja herencia allendista. En: Zerán, Faride. Chile actual: crisis y debate desde las izquierdas. Santiago: LOM Ediciones, pp. 17-25.

Ampuero, R. (2002). El socialismo chileno. Santiago: Ediciones Tierra Mía.

Arrate, J. y Ruiz, C. (2020). Génesis y ascenso del socialismo chileno. Una antología hasta 1973. Santiago: LOM Ediciones.

Cortés Terzi, A. (1988). "Salvador Allende y el allendismo posible”, Revista Avances, (7), pp. 6-34.

(1989). "Antonio Gramsci y sus críticas al dogmatismo", Cuadernos Avance, (1), pp. 54-68.

(1989). Gramsci: teoría politica. Ensayo de interpretación y divulgación política. Santiago: América Latina Libros.

Elgueta, B. (2015). El socialismo en Chile. Una herencia yacente. Santiago: Tiempo Robado Editoras.

Faletto, E. (2016). Faletto latinoamericano. Artículos y ensayos. Santiago: Editorial Universitaria.

(2009) Síntesis histórica del Partido Socialista chileno. Desde los orígenes hasta 1970. En: Baño, R., Ruiz, C., Ruiz-Tagle, M.E. (edits.) Enzo Faletto. Obras Completas Tomo I. Santiago: Editorial Universitaria, pp. 207-225.

Garcés, J. (2013). Allende y la experiencia chilena. Las armas de la política. Madrid: Siglo XXI.

Poulantzas, N. (1980). La crise des partis. En: Reperes, París, Dialectiques Intervertions, pp. 163-184.

Quiroga, P. (2016). La dignidad de América. El retorno histórico a Salvador Allende. Santiago: Escaparate. 